Case Reports
in Dermatology

\title{
Embolia Cutis Medicamentosa after Subcutaneous Injection with Glatiramer Acetate
}

\author{
Lyubomira Vlahova Lutz Kretschmer Michael P. Schön \\ Rotraut Mössner \\ Department of Dermatology, Venereology and Allergology, University Medical Center \\ Göttingen, Göttingen, Germany
}

\section{Keywords}

Embolia cutis medicamentosa $\cdot$ Glatiramer acetate $\cdot$ Injection site reaction

\begin{abstract}
Embolia cutis medicamentosa (ECM) is a rare and unpredictable injection site reaction, occurring after intramuscular, subcutaneous, and even after intraarticular injection of various drugs. We report a very rare case of necrotizing ECM after injection of glatiramer acetate for multiple sclerosis, include a photo documentation over the entire disease course, and discuss hypotheses as to etiology and treatment.

(c) 2021 The Author(s)

Published by S. Karger AG, Basel
\end{abstract}

\section{Introduction}

Copaxone ${ }^{\circledR}$ (glatiramer acetate, GA) is a mixture of synthetic tetrapeptides which reduces relapse frequency in patients with relapsing-remitting multiple sclerosis. Its most common side effects are injection site reactions, such as erythema, pain, and pruritus, and immediate postinjection reactions, such as dyspnea, flushing, and tachycardia [1, 2]. We report a patient who developed embolia cutis medicamentosa (ECM) as a severe injection site reaction. 


\section{Case Reports in Dermatology}

\section{Case Report/Case Presentation}

A 55-year-old man with a 5-year history of multiple sclerosis had been treated subcutaneously for 4 years with GA $40 \mathrm{mg} 3$ times weekly. He changed injection sites every time (abdomen, ventral thighs, buttocks) and experienced occasional mild injection site reactions with coin-sized skin swelling and induration which resolved within weeks. Approximately $30 \mathrm{~s}$ after the last injection in the lower left abdomen the patient experienced a sudden-onset intense, radiating pain. Two minutes later, he developed an extended urticarial swelling with erythematous borders mainly on the left side of his abdomen. The irregular reticular and serrated lesions also extended to the right side (Fig. 1a). There were no systemic symptoms. He was treated with intravenous glucocorticoids and the swelling resolved within hours.

Two days later, a livid erythematous macula with irregularly serrated margins developed. The patient suffered from severe abdominal pain and was admitted to hospital. He received intravenous meropenem and linezolid for 2 days.

A week later, he presented at our department with a well-demarcated reticular erythema of $10 \times 15 \mathrm{~cm}$ with central blisters and peripheral induration (Fig. 1b). Routine blood test revealed mildly increased C-reactive protein and creatine kinase, serological autoimmune parameters including autoantibodies to extractable nuclear antigens and double stranded DNA, lupus anticoagulant, and cryoglobulins were negative. Skin swabs showed resident flora. Ultrasound showed a diffuse increase in echogenicity of subcutaneous tissue (Fig. 2), as nonspecific demonstration of inflammation, observed for example in lymphedema and cellulitis [3]. Histopathologically, there was necrosis of the epithelium and sweat glands, thrombosed small vessels, neutrophil infiltration and hematoma in the dermis, but no evidence of primary vasculitis (Fig. 3). Direct immunofluorescence was without pathological findings. We made the diagnosis of ECM. Vascular thrombosis and cutaneous necrosis in the absence of signs of vasculitis are the histological hallmarks of ECM [4].

Over the next 6 weeks, the necrotic area demarcated and continued to extend. Surgical debridement, vacuum-assisted closure therapy, topical antiseptics, and dressings led to complete resolution and formation of an atrophic scar during the following 12 weeks (Fig. 1c-f). After this episode, the patient refused to resume GA therapy.

\section{Discussion/Conclusion}

ECM, also termed Nicolau syndrome, was first described by Freudenthal and Nicolau in 1924 and 1925, respectively, after intramuscular injection of bismuth salts in syphilis patients $[5,6]$. It typically presents with sudden-onset, severe pain occurring immediately after the injection, followed by swelling, bizarre-looking erythema, and induration within hours [7]. The peripheral erythema diminishes within days. Blisters can occur as a sign of skin damage. Necrotic areas demarcate within several weeks [7]. Several cases of ECM have been reported after intramuscular, subcutaneous, and even after intraarticular injection of various drugs, such as non-steroidal anti-inflammatory drugs (NSAIDs), vitamin K, vitamin B12, penicillin, antihistamines, corticosteroids, local anesthetics, vaccines, and interferon- $\alpha$ and $-\beta[8,9]$. There are only few descriptions of necrotic ECM after treatment with GA (20 and $40 \mathrm{mg} /$ day) $[7,8,10-14]$. In 2 of these patients, further injections of GA led to another episode of ECM after well-tolerated injections in-between $[10,11]$. Thus, ECM remains unpredictable and does not necessarily contraindicate continuation of the treatment $[10,11]$. Injection site reactions were

\section{Karger'=}




\section{Case Reports in Dermatology}

\begin{tabular}{l|l}
\hline Case Rep Dermatol 2021;13:114-120 \\
\hline DOI: 10.1159/000510017 & $\begin{array}{l}\text { c 2021 The Author(s). Published by S. Karger AG, Basel } \\
\text { www.karger.com/cde }\end{array}$ \\
\hline
\end{tabular}

Vlahova et al.: Embolia Cutis Medicamentosa after Subcutaneous Injection with Glatiramer Acetate

the most common adverse events in a randomized placebo-controlled trial with GA $40 \mathrm{mg} 3$ times weekly (35.2\% over 12 months in GA-treated patients compared to $5 \%$ in placebotreated patients) [1]. After 3 years of follow-up, there were no cases of skin necrosis in the open-label extension study of Khan et al. [2]. The pathogenesis of ECM remains poorly understood. Various factors may play a role, including accidental intravascular injection with embolic occlusion, reflexive vasospasm, and vascular rupture with perivascular inflammation and cytotoxic reaction to the drug [15]. In addition, lipophilic drugs may penetrate the blood vessels and induce physical occlusion as a more drug-specific reaction. The differential diagnosis of ECM includes direct drug-related cutaneous toxicity including skin necrosis, more commonly seen with interferon- $\beta$, occurring multilocularly and not accompanied by intense immediate pain [7]. No standard therapy exists for ECM. Recommendations depend on severity and include analgesics, antibiotics, anticoagulants, and topical or systemic corticosteroids. In case of necrosis, therapy also includes local dressings and surgical debridement $[7,8,15]$.

In conclusion, development of ECM is rare and cannot be avoided despite correct injection technique including aspiration. It is unpredictable and discontinuation of the therapy should depend on careful consideration of risks and benefits in the individual setting.

\section{Statement of Ethics}

This case report was conducted ethically in accordance with the World Medical Association Declaration of Helsinki. The patient has given his written informed consent to use images and clinical information in scientific publications without publishing of his name and initials.

\section{Conflict of Interest Statement}

The authors have no conflicts of interest to declare.

\section{Funding Sources}

The authors have no funding sources to declare.

\section{Author Contributions}

All named authors took care of the patient, took responsibility for the integrity of the work as a whole, and gave final approval to the version to be published.

\section{References}

1 Khan O, Rieckmann P, Boyko A, Selmaj K, Zivadinov R; GALA Study Group. Three times weekly glatiramer acetate in relapsing-remitting multiple sclerosis. Ann Neurol. 2013 Jun;73(6):705-13.

2 Khan O, Rieckmann P, Boyko A, Selmaj K, Ashtamker N, Davis MD, et al. Efficacy and safety of a three-timesweekly dosing regimen of glatiramer acetate in relapsing-remitting multiple sclerosis patients: 3-year

\section{Karger'=}




\section{Case Reports in Dermatology}

\begin{tabular}{l|l}
\hline Case Rep Dermatol 2021;13:114-120 \\
\hline DOI: 10.1159/000510017 & $\begin{array}{l}\text { @ 2021 The Author(s). Published by S. Karger AG, Basel } \\
\text { www.karger.com/cde }\end{array}$ \\
\hline
\end{tabular}

Vlahova et al.: Embolia Cutis Medicamentosa after Subcutaneous Injection with Glatiramer Acetate

results of the Glatiramer Acetate Low-Frequency Administration open-label extension study. Mult Scler. 2017 May;23(6):818-29.

3 Suehiro K, Morikage N, Murakami M, Yamashita O, Samura M, Hamano K. Significance of ultrasound examination of skin and subcutaneous tissue in secondary lower extremity lymphedema. Ann Vasc Dis. 2013;6(2):180-8.

4 Tabor D, Bertram CG, Williams AJ, Mathers ME, Biswas A. Nicolau Syndrome (Embolia Cutis Medicamentosa): A Rare and Poorly Recognized Iatrogenic Cause of Cutaneous Thrombotic Vasculopathy. Am J Dermatopathol. 2018 Mar;40(3):212-5.

5 Freudenthal W. Lokales embolisches Bismogenol-Exanthem. Arch Dermatol Syph. 1924;147(1):155-60.

6 Nicolau S. Dermite livedoide et gangreneuse de la fesse, consecutive aux injections intramusculaires dans la syphilis. Ann Mal Venereol. 1925;20:321-9.

7 Harde V, Schwarz T. Embolia cutis medicamentosa following subcutaneous injection of glatiramer acetate. J Dtsch Dermatol Ges. 2007 Dec;5(12):1122-3.

8 Koller S, Kränke B. Nicolau syndrome following subcutaneous glatiramer-acetate injection. J Am Acad Dermatol. 2011 Feb;64(2):e16-7.

9 Luton K, Garcia C, Poletti E, Koester G. Nicolau Syndrome: three cases and review. Int J Dermatol. 2006 Nov;45(11):1326-8.

10 Zecca C, Mainetti C, Blum R, Gobbi C. Recurrent Nicolau syndrome associated with subcutaneous glatiramer acetate injection-a case report. BMC Neurol. 2015 Dec;15(1):249.

11 Martínez-Morán C, Espinosa-Lara P, Nájera L, Romero-Maté A, Córdoba S, Hernández-Núñez A, et al. Embolia cutis medicamentosa (síndrome de Nicolau) tras inyección de acetato de glatirámero. Actas Dermosifiliogr. 2011 Nov;102(9):742-4

12 Kimbrough DJ, Newsome SD. Case Report: Two Cases of Nicolau Syndrome Associated with Glatiramer Acetate. Int J MS Care. 2017 May-Jun;19(3):148-50.

13 Wolinsky JS, Borresen TE, Dietrich DW, Wynn D, Sidi Y, Steinerman JR, et al.; GLACIER Study Group. GLACIER: an open-label, randomized, multicenter study to assess the safety and tolerability of glatiramer acetate $40 \mathrm{mg}$ three-times weekly versus $20 \mathrm{mg}$ daily in patients with relapsing-remitting multiple sclerosis. Mult Scler Relat Disord. 2015 Jul;4(4):370-6.

14 Blind A, Lenormand C, Schissler C, Cribier B, Lipsker D. [Suprapubic Nicolau syndrome following subcutaneous injection of glatiramer acetate]. Ann Dermatol Venereol. 2018 Nov;145(11):671-5.

15 Kim SK, Kim TH, Lee KC. Nicolau syndrome after intramuscular injection: 3 cases. Arch Plast Surg. 2012 May;39(3):249-52. 


\section{Case Reports in Dermatology}
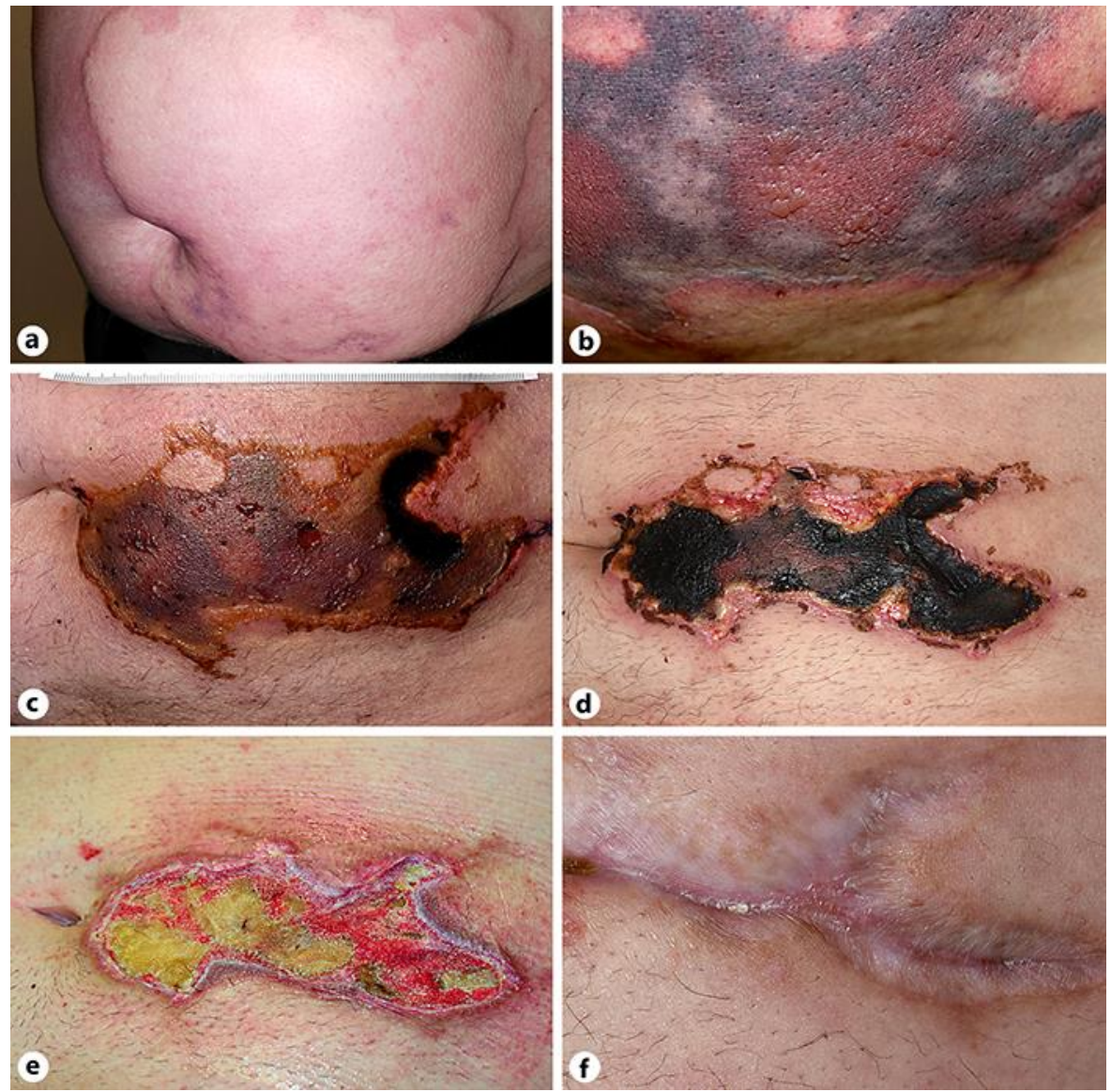

Fig. 1. a Extended urticarial swelling with erythematous borders mainly on the abdomen 2 min after subcutaneous injection with glatiramer acetate. $\mathbf{b}$ Livedo-like erythema, centrally with bullae formation on day 8. c, d Demarcated necrotic area (days 17 and 24, respectively). e Lesion after surgical wound debridement and under vacuum-assisted closure therapy (day 57). f Atrophic scar (day 173). 


\section{Case Reports in Dermatology}

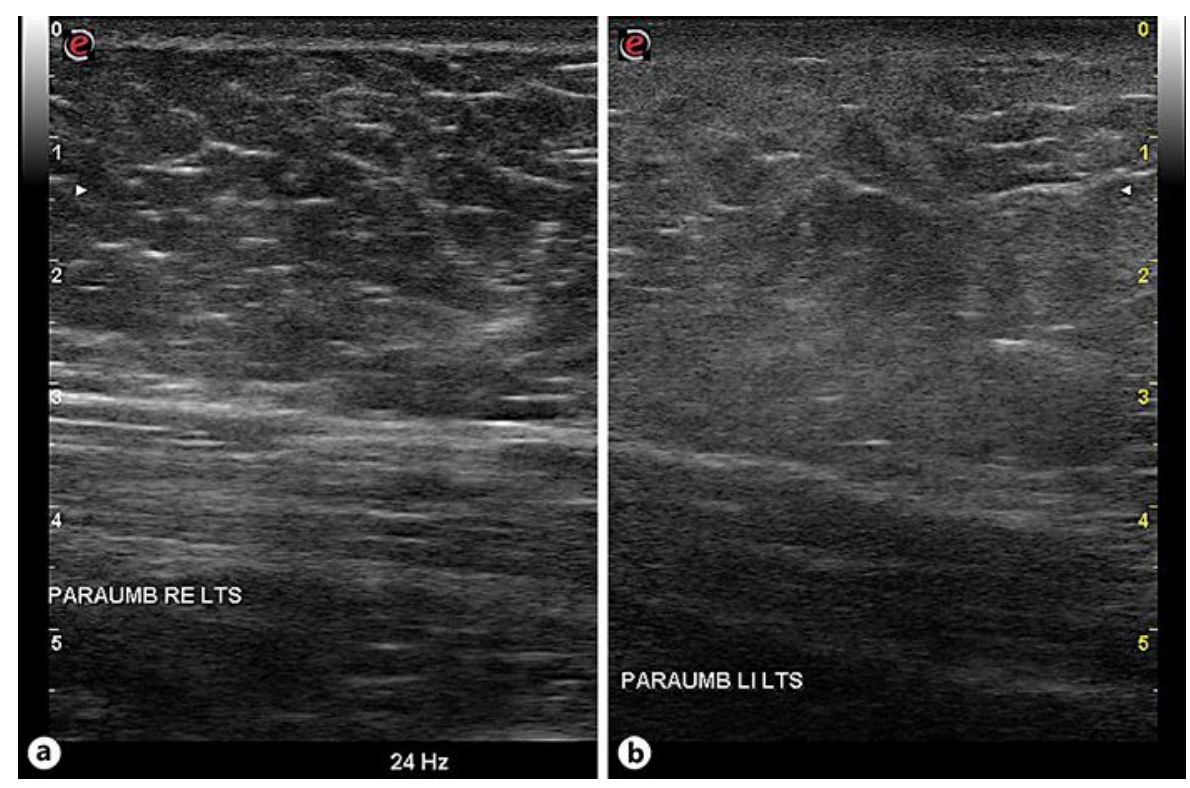

Fig. 2. Dermatological ultrasound paraumbilically on the right (a) and left abdomen (b). On the primarily affected left abdomen (b), diffuse increase in the echogenicity of the fatty lobules with unclear borders to the septa is seen compared to the clinically only slightly affected right abdomen (a). 


\section{Case Reports in Dermatology}

\begin{tabular}{l|l}
\hline Case Rep Dermatol 2021;13:114-120 \\
\hline DOI: 10.1159/000510017 & $\begin{array}{l}\text { ( ) 2021 The Author(s). Published by S. Karger AG, Basel } \\
\text { www.karger.com/cde }\end{array}$ \\
\hline
\end{tabular}

Vlahova et al.: Embolia Cutis Medicamentosa after Subcutaneous Injection with Glatiramer Acetate

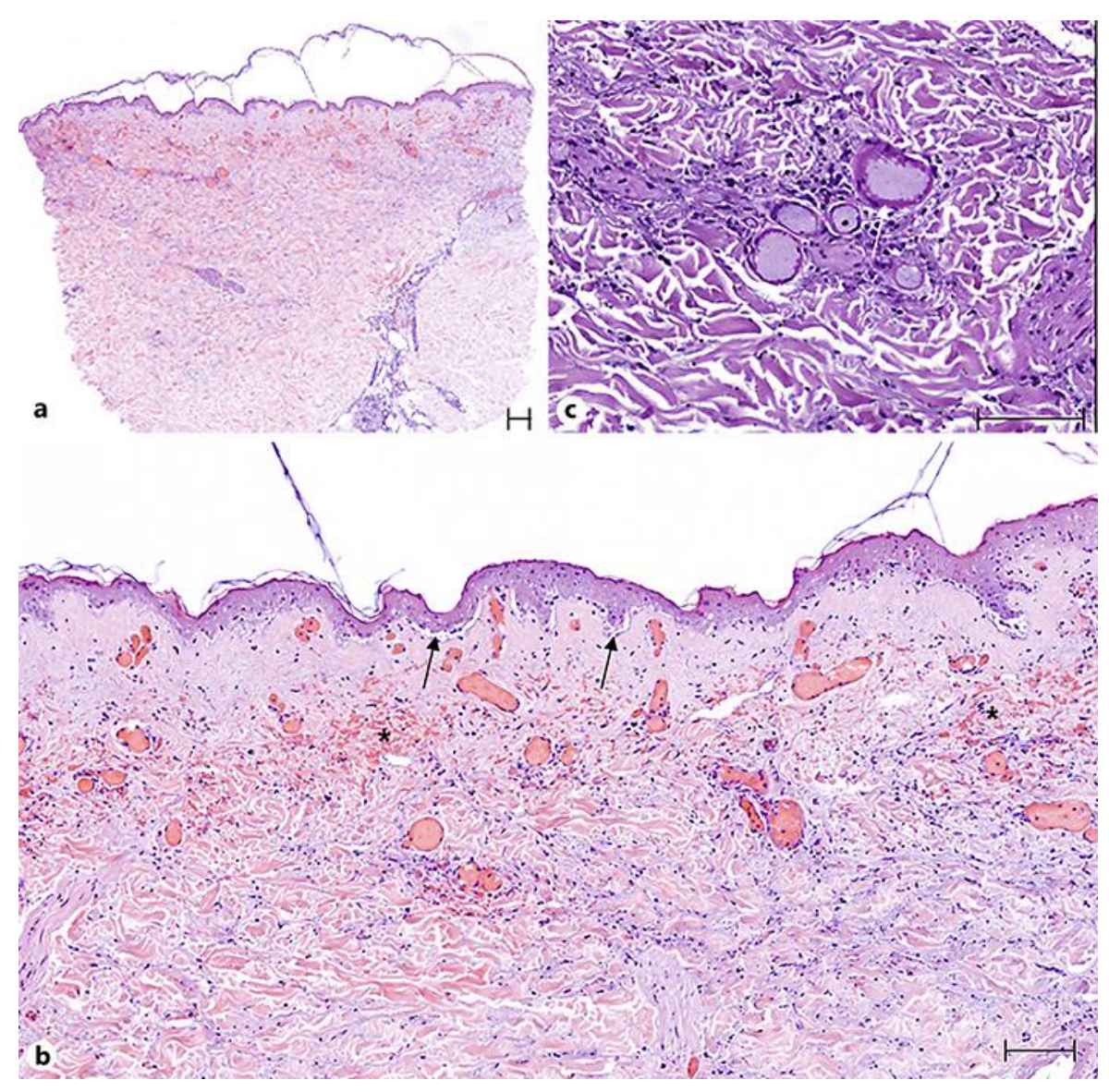

Fig. 3. HE staining (a, b) of a biopsy specimen shows necrobiotic epidermis with subepidermal cleft formation (exemplified by arrows in b), dilated and congested blood vessels in the dermis and erythrocyte extravasates (asterisks in b). PAS staining (c) also reveals fibrinoid degeneration of individual blood vessels (arrow in c). Scale bars, $100 \mu \mathrm{m}$. 